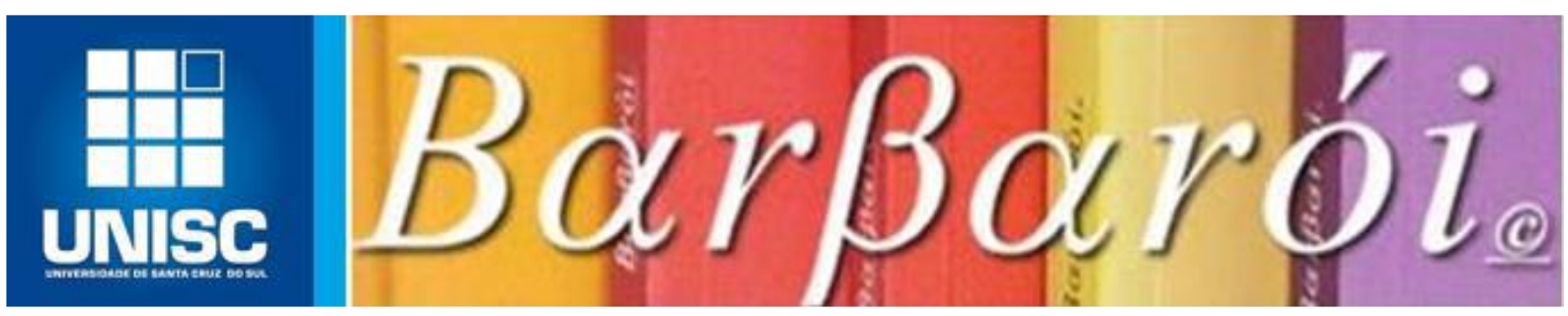

\title{
O DESCOMPASSO ENTRE AS POLÍTICAS E OS INDICADORES HABITACIONAIS NO BRASIL: UMA ANÁLISE EM MUNICÍPIOS DO ESTADO DO RIO GRANDE DO SUL
}

\author{
DOI: http://dx.doi.org/10.17058/barbaroi.v0i0.14726 \\ $*$
}

Helena de Moura Vogt

Universidade de Santa Cruz do Sul - UNISC-Brasil

Rogério Leandro Lima da Silveira

Universidade de Santa Cruz do Sul - UNISC - Brasil

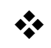

\section{Resumo}

A intensa e desigual urbanização das cidades brasileiras tem se caracterizado por apresentar, entre outros problemas, um recorrente déficit habitacional, advindo de um especulativo mercado imobiliário e da falta ou insuficiência de políticas públicas habitacionais inclusivas. Mas qual é de fato a realidade da situação habitacional brasileira? Os objetivos e a implementação da recente política habitacional nacional levam efetivamente em conta os indicadores existentes sobre o déficit habitacional e o número de imóveis urbanos vagos nos municípios brasileiros? Esse artigo discute brevemente essas questões e as incongruências existentes entre os objetivos das políticas habitacionais recentes e a real situação do déficit habitacional urbano no Brasil, analisando mais especificamente esse processo em municípios selecionados do Rio Grande do Sul. Metodologicamente, a análise é realizada a partir da correlação de dados secundários da Fundação João Pinheiro (FJP), do Instituto Brasileiro de Geografia e Estatística (IBGE) e da Caixa Federal referente aos indicadores de população municipal, déficit habitacional urbano, $\mathrm{n}^{\circ}$ de domicílios vagos urbanos e produção habitacional do Programa habitacional Minha Casa Minha Vida-MCMV(Faixa 1), em municípios de 75.000 a 300.000 habitantes no Estado do Rio Grande do Sul. Conclui-se que há descompassos entre os objetivos das políticas e indicadores da real situação habitacional, evidenciando a necessidade de avaliações e monitoramento das políticas públicas no território que observem e valorizem os indicadores habitacionais dos municípios.

Palavras-chave: Política Habitacional; Indicadores habitacionais; Minha Casa Minha Vida. 


\section{Introdução}

O intenso e desigual processo de urbanização experimentado pelas cidades brasileiras nos últimos cinquenta anos tem se caracterizado por apresentar um conjunto de problemas urbanos. Entre eles há a existência de um recorrente déficit habitacional que assegurem o direito à habitação e à cidade ao conjunto da população, especialmente à população de baixa renda, advindo de: aumento da população urbana; especulativo mercado imobiliário; e falta ou insuficiência de políticas públicas habitacionais inclusivas.

Mas qual é de fato a realidade da situação habitacional brasileira? Como se apresentam os dados relativos ao déficit habitacional e aos domicílios vagos nas cidades brasileiras? Os objetivos e a implementação da recente política habitacional nacional levam efetivamente em conta os indicadores existentes sobre o déficit habitacional e o número de imóveis urbanos vagos nos municípios brasileiros? Esse artigo discute brevemente essas questões e as incongruências existentes entre os objetivos das políticas habitacionais recentes e a real situação do déficit habitacional urbano no Brasil, analisando mais especificamente esse processo em municípios selecionados do Rio Grande do Sul.

As questões e análises que abordamos aqui sobre as incongruências entre a política habitacional brasileira e a realidade do déficit e da situação habitacional do país decorrem das reflexões iniciais que surgiram a partir da pesquisa que estamos realizando no âmbito do Grupo de Pesquisa e Estudos Urbanos e Regionais (GEPEUR), UNISC-CNPq sobre o processo de alterações na configuração territorial urbana da cidade média de Santa Cruz do Sul a partir das ações produzidas pela rede de agentes imobiliárias e pelas políticas habitacionais federais no contexto do aparente déficit habitacional do município. Portanto, o objetivo do artigo foi analisar as incongruências e os descompassos entre a produção de habitações realizadas pelo Programa Minha casa Minha Vida (MCMV) estimulada pela recente Política Habitacional do governo federal brasileiro e indicadores da situação habitacional no país, como o déficit habitacional urbano e $\mathrm{n}^{\mathrm{o}}$ de domicílios vagos urbanos existentes em municípios de 75.000 a 300.000 habitantes, no Estado do Rio Grande do Sul.

O artigo além dessa introdução está constituído de outros dois tópicos. No primeiro, aborda-se sucintamente a evolução das políticas habitacionais e o déficit habitacional brasileiro. No segundo e último tópico, aborda-se como se apresenta a questão habitacional no estado do Rio Grande do Sul, através da análise dos dados secundários sobre a dinâmica de crescimento da população urbana, o déficit habitacional urbano e os domicílios vagos urbanos e sua correlação com os dados do Programa MCMV, nas cidades selecionadas para o estudo. 


\section{As políticas habitacionais e o déficit habitacional brasileiro}

Dentre os muitos problemas e necessidades que sempre afligiram a população dos maiores centros urbanos do Brasil, Bolaffi (1976) já destacava: a falta de alimentação adequada; a falta de atendimento médico; a falta de transportes satisfatórios entre o domicílio e o trabalho; a falta de oportunidades educacionais; a falta de condições satisfatórias de habitação e de serviços públicos; e principalmente a falta de renda para adquirir os bens de serviços acima referidos. Contudo, em 1964, o Governo Federal elege a habitação popular como "problema fundamental". Tornando o BNH (Banco Nacional da Habitação) o segundo banco do país em termos de magnitude de recursos disponíveis para o financiamento de habitações precedido pelo Banco do Brasil. Assim, a produção de habitação em conjunto com as inspirações da população brasileira pela casa própria, aumentou o $\mathrm{n}^{\circ}$ de habitações produzidas e a necessidade de uma moradia para um dos problemas que afligiam o Brasil, o déficit habitacional.

Entretanto, de acordo com Bolaffi (1976), pelo relatório anual do BNH de 1971 os recursos utilizados pelo Sistema Financeiro da Habitação só foram suficientes para atender 24\% da demanda populacional urbana. Sendo que no mesmo ano o déficit habitacional aumentou 76\%. Ou seja, segundo Bolaffi (1976), um dos motivos para o BNH não conseguir atingir seus objetivos seria seu modo de operação e mecanismos de seu funcionamento. Pois, suas operações eram transmitidas para a iniciativa privada, já que o banco se limitava a arrecadar os recursos financeiros.

Assim, ao transferir para a iniciativa privada todas as decisões sobre a localização e a construção das habitações, o crédito habitacional tornou-se uma mercadoria que supriu a necessidade da casa própria da sociedade brasileira, mas não suas carências diversas. Isso ocorreu, embora tenha-se produzido entre 1964 a 1986, 4 milhões de unidades habitacionais (i.e., número esse que até hoje não foi superado por nenhuma outra política habitacional no país (SILVA et TOURINHO, 2015).

Conforme Azevedo e Andrade (1982) as atividades do BNH, então, ligadas ao déficit habitacional nos primeiros trinta anos tinham mostrado que não bastava apenas construir casas, era preciso dotá-las de infraestrutura adequada. Sendo, dessa forma, que não foram poucos os conjuntos operários que cedo começaram a apresentar sinais de rápida deterioração das casas e do ambiente. Assim, após anos na tentativa de lidar com o problema habitacional, desde o início da atuação do BNH, o modelo de política habitacional implementado a partir de 1964, pelo Banco Nacional de Habitação (BNH), acabou extinto.

Por não conseguir superar a crise do Sistema Financeiro da Habitação (SFHA) a extinção do BNH criou um hiato em relação à política habitacional no País. Como consequência Barbarói, Santa Cruz do Sul, n. 56, p.<261-281>,jan./jun. 2020 
a desarticulação progressiva da instância federal, a fragmentação institucional, a perda de capacidade decisória e a redução significativa dos recursos disponibilizados para investimento na área.

De fato, a crise do setor habitacional foi resultado de uma descentralização por ausência, já que não houve uma repartição clara e institucionalizada de competências e responsabilidades. Além do mais, o governo federal não definiu incentivos e alocou recursos significativos para que os governos dos estados e municípios pudessem oferecer programas habitacionais de fôlego para enfrentar o problema (MINISTÉRIO DAS CIDADES, 2004).

Em 2003, o então governo do presidente Luiz Inácio Lula da Silva começou a implementar mudanças nesse quadro com a criação do Ministério das Cidades, que passava a ser o órgão responsável pela Política de Desenvolvimento Urbano e, dentro dela, pela Política Setorial de Habitação. Integram o Ministério das Cidades: a Secretaria Nacional de Habitação, a Secretaria Nacional de Programas Urbanos, a Secretaria Nacional de Saneamento Ambiental e a Secretaria Nacional de Transporte e Mobilidade Urbana. A Política de Habitação se inscreve dentro da concepção de desenvolvimento urbano integrado, no qual, então, a habitação não se restringe a casa, incorpora também o direito à infraestrutura, saneamento ambiental, mobilidade e transporte coletivo, equipamentos e serviços urbanos e sociais, buscando garantir direito à cidade (MINISTÉRIO DAS CIDADES, 2004).

Logo, a Política Nacional de Habitação, realizada pelo Ministério das Cidades, criada em 2003, foi desenvolvida em coerência com a Constituição Federal. Dessa forma considerou a habitação um direito do cidadão seguindo o Estatuto da Cidade, que estabeleceu a função social da propriedade como as diretrizes do então governo (i.e., de 2004), que preconizava a inclusão social, a gestão participativa e democrática. Descarte, essa Política Nacional de Habitação visou promover as condições de acesso à moradia digna a todos os segmentos da população, especialmente o de baixa renda, contribuindo, assim, para a inclusão social.

Seus objetivos tornaram-se mais amplos do que o combate ao déficit habitacional, tais como: universalizar o acesso à moradia digna, levando-se em conta a disponibilidade de recursos existentes no sistema, a capacidade operacional do setor produtivo e da construção, e dos agentes envolvidos na implementação da PNH (Política Nacional de Habitação); promover a urbanização, regularização e inserção dos assentamentos precários à cidade; fortalecer o papel do Estado na gestão da Política e na regulação dos agentes privados; tornar a questão habitacional uma prioridade nacional, integrando, articulando e mobilizando os diferentes níveis de governo e fontes, objetivando potencializar a capacidade de investimentos com vistas a viabilizar recursos para sustentabilidade da $\mathrm{PNH}$; democratizar o acesso à terra urbanizada e Barbarói, Santa Cruz do Sul, n. 56, p.<261-281>,jan./jun. 2020 
ao mercado secundário de imóveis; ampliar a produtividade e melhorar a qualidade na produção habitacional; e incentivar a geração de empregos e renda dinamizando a economia, apoiandose na capacidade que a indústria da construção apresenta em mobilizar mão-de-obra, utilizar insumos nacionais sem a necessidade de importação de materiais e equipamentos e contribuir com parcela significativa do Produto Interno Bruto (PIB).

Dessa forma, a constituição da Política Nacional de Habitação reconheceu os principais pontos a serem tratados no que se refere a habitação e a economia. E a partir desse reconhecimento, ela contou com um conjunto de instrumentos a serem criados, pelos quais se viabilizou sua implementação. São eles: o Sistema Nacional de Habitação (SNH), o Desenvolvimento Institucional, o Sistema de Informação, Avaliação e Monitoramento da Habitação (SIMAHAB), e o Plano Nacional de Habitação (PNH).

O Sistema de Informação, Avaliação e Monitoramento da Habitação (SIMAHAB), parte integrante do Sistema Nacional de Informações das Cidades (SNIC), no âmbito geral da Política de Informações (PIC) do Ministério das Cidades, foi criado como instrumento estratégico para garantir um processo permanente de revisão e redirecionamento da política habitacional e de seus programas. Sendo que esse instrumento tinha como intuito prever o desenvolvimento de uma base de informações, o monitoramento e a avaliação permanente dos projetos e programas da Política Nacional de Habitação. Portanto, o objetivo geral foi implantar um Sistema de Informações Habitacionais (georreferenciado) que servisse de instrumento para: 1) a quantificação, qualificação e avaliação das condições de moradia nas cidades brasileiras, em suas diferentes dimensões (social, econômica, administrativa, jurídica, financeira e funcional), considerando diversos níveis de desagregação espacial e socioeconômica; 2) a formulação, a implementação, o monitoramento e a avaliação das políticas públicas na área de habitação, qualificando os obstáculos que se interpõem ao alcance das metas programáticas e avaliando os impactos dessas políticas para a solução dos problemas habitacionais brasileiros.

Quanto, ao Plano Nacional de Habitação (PlanHab) ele foi um dos mais importantes instrumentos para a implementação dessa Política Nacional de Habitação. Previsto na Lei 11.124/05, que estruturou o Sistema Nacional de Habitação de Interesse Social foi elaborado por meio de um intenso processo participativo, que contou com a presença de todos os segmentos sociais relacionados com o setor habitacional (i.e. de acordo com o documento elaborado pelo Ministério das Cidades). Foram incorporados a ele os dois principais programas habitacionais em curso no país, o Programa de Aceleração do Crescimento (PAC) e o Programa Minha Casa Minha Vida (PMCMV) (MINISTÉRIO DAS CIDADES, 2004).

Observa-se, então que essa Política Nacional de Habitação teve como objetivo uma Barbarói, Santa Cruz do Sul, n. 56, p.<261-281>,jan./jun. 2020 
implementação gradual e ampla. Com diversos instrumentos que buscaram enfrentar problemas encontrados pelo diagnóstico sobre a questão habitacional, tais como: o déficit habitacional quantitativo e qualitativo, a questão fundiária, o problema dos domicílios vagos, a fragmentação do espaço urbano, o contínuo crescimento e adensamento da periferia urbana, os assentamentos precários e os problemas de financiamento e o mercado imobiliário.

Entretanto, ao observar esses objetivos com indicadores fornecidos pela Fundação João Pinheiro (FJP) Centro de Estatísticas e Informações de Minas Gerais e dados de unidades habitacionais Minha Casa Minha Vida - Faixa 1 da CAIXA, infere-se que no Brasil, não se obteve uma gestão do território por oferta e demanda habitacional. Já que o $\mathrm{n}^{\circ}$ de domicílios urbanos vagos e o déficit habitacional total, continuou alto em 2015 (Tabela 1). O número de domicílios vagos e o $\mathrm{n}^{\circ}$ de domicílios particulares permanentes somente cresceu (Tabela 1 e 2). Mesmo com o aumento percentual de domicílios particulares permanentes urbanos ter sido superior ao aumento percentual da população de 2000 a 2010 (Tabela 2), o déficit habitacional continuou alto em 2010 (Tabela 1). E o número de unidades habitacionais MCMV para faixa 1 entre os anos de 2010 e 2018 foi somente de 1.430.306, sendo 24\% do déficit habitacional urbano de 2010, e 25\% do déficit de 2015.

Tabela 1 - Variáveis Brasil 2000/2010/2015 (déficit habitacional e domicílios vagos)

\begin{tabular}{c|ccccc}
\hline & $\begin{array}{c}\text { déficit hab. } \\
\text { total }\end{array}$ & $\begin{array}{c}\text { déficit hab. } \\
\text { total relativo }\end{array}$ & $\begin{array}{c}\text { déficit hab. } \\
\text { urbano }\end{array}$ & $\begin{array}{c}\text { domicílios } \\
\text { vagos total }\end{array}$ & $\begin{array}{c}\text { domicílios } \\
\text { vagos urbano }\end{array}$ \\
\hline 2000 & 5.890 .139 & $13,15 \%$ & 4.140 .088 & 6.029 .756 & 4.580 .147 \\
2010 & 6.940 .691 & $12,1 \%$ & 5.885 .528 & 6.052 .161 & 4.656 .978 \\
2015 & 6.355 .743 & $9,3 \%$ & 5.572 .700 & 7.906 .767 & 6.350 .010
\end{tabular}

Fonte: Formulação da tabela pela autora a partir de dados fornecidos pela Fundação João Pinheiro.

Tabela 2 - Variáveis Brasil 2000/2010 (população e domicílios particulares permanentes)

\begin{tabular}{c|cccc}
\hline & População & $\begin{array}{c}\text { Aumento pop. \% ao } \\
\text { ano anterior }\end{array}$ & $\begin{array}{c}\text { Dom. particular } \\
\text { permanente urbano }\end{array}$ & $\begin{array}{c}\text { Aumento dom. \% ao } \\
\text { ano anterior }\end{array}$ \\
\hline 2000 & 169.799 .170 & - & 37.369 .980 & - \\
2010 & 190.732 .694 & $112 \%$ & 49.228 .253 & $132 \%$ \\
\hline
\end{tabular}

Fonte: Formulação da tabela pela autora a partir de dados fornecidos pela Fundação João Pinheiro.

E, da mesma forma Domingos \& Fernandes J. (2017) relatam que ao compararem os resultados entre o déficit habitacional e o número de domicílios vagos o resultado foi

1 Com potencial a serem ocupados.

Barbarói, Santa Cruz do Sul, n. 56, p.<261-281>, jan./jun. 2020 
discrepante. No ano de 2014 a carência por domicílios era de 6 milhões e o contingente de moradias desocupadas era de 7,2 milhões, um excedente de mais 1,1 milhões de unidades. Mesmo selecionando apenas os domicílios como capacidade de ocupação ou em reformas o quantitativo superou as 7 milhões de unidades habitacionais. Ademais, Bonduki (2008) também revela que se fosse possível utilizar o número de imóveis vagos para alojar famílias necessitadas de moradia, seria possível sanar $83 \%$ do déficit nacional de unidades urbanas, sendo que em algumas regiões metropolitanas o número de domicílios vagos poderia ultrapassar o déficit quantitativo. Além de que a existência de um número tão significativo de imóveis vagos gera: 1) deterioração do edifício e do entorno; 2) grave problema urbano, com o despovoamento de áreas bem servidas de equipamentos e empregos; 3) migração da população para regiões desprovidas e distantes, multiplicando as necessidades de investimentos públicos. Portanto, dentre os objetivos da Política/Plano Nacional de Habitação e do Programa MCMV, o problema da existência e ampliação de domicílios vagos aliado à superprodução de novas unidades habitacionais para relativizar o déficit habitacional acabou indo em contraponto, ou mesmo se mostrando contraditório aos demais objetivos da própria política, isto é, a fragmentação do espaço urbano, a questão fundiária, os assentamentos precários e o contínuo crescimento e adensamento da periferia urbana.

Contudo, mesmo que Sistema de Informação, Avaliação e Monitoramento da Habitação (SIMAHAB) tenha buscado acrescentar significativas mudanças no programa MCMV, a partir da contratação do estudo "Déficit Habitacional no Brasil - Municípios Selecionados e Microrregiões Geográficas - 2000” fornecidos pela Fundação João Pinheiro2, os indicadores evidenciam que não se obteve a evolução dos objetivos da Política Habitacional. Em primeiro lugar, pois as informações foram insuficientes e dispersas entre inúmeras instituições e não disponíveis com os níveis de desagregação necessários para caracterizar as desigualdades regionais e socioeconômicas sobre o setor habitacional. Em segundo lugar, pois somente após a criação da Política/Plano o Programa começou-se a ter acesso aos dados fornecidos pela FJP, apesar dos mesmos só serem atualizados a partir do censo (a cada 10 anos) e, em alguns casos, a retirada de uma ou outra variável pode inviabilizar, inclusive, a comparação das estimativas.

Assim, a Política Nacional de Habitação que propunha um Sistema de Informação, Avaliação e Monitoramento da Habitação parece não ter tido para a implementação dos primeiros programas habitacionais nos municípios, uma fonte precisa, anual, georreferenciada,

\footnotetext{
${ }^{2}$ Por meio de parceria com o Programa das Nações Unidas para o Desenvolvimento (PNUD), o Banco Interamericano de Desenvolvimento (BID) e o Ministério das Cidades.
}

Barbarói, Santa Cruz do Sul, n. 56, p.<261-281>,jan./jun. 2020 
com software livre e agentes públicos qualificados para o monitoramento e avaliação das construções habitacionais. Porém, após os primeiros anos de Programa com a disponibilidade de indicadores sobre o déficit habitacional urbano e o $\mathrm{n}^{\mathrm{o}}$ de domicílios vagos urbanos municipal de 2000 e 2010, fornecido pela Fundação João Pinheiro, o Programa MCMV continuou comprometendo os objetivos da política pública de habitação em relação a localização periférica dos empreendimentos do MCMV, e ao precário conteúdo das áreas escolhidas para sua implantação quanto às condições de acesso à infraestrutura e equipamentos urbanos necessários para os novos moradores. Conforme a auditoria do TCU, pelo Jornal do Senado (2018), o MCMV continuam comprometendo a habitação territorial pela falta de equipamentos públicos próximos $(73,4 \%$ dos moradores sofrem com a falta de escolas e creches nas redondezas, 70,2\% afirmam não ter unidade básica de saúde, $68,1 \%$ não têm comércio próximo e 46,8\% julgam o transporte público insuficiente para a demanda). Criando-se assim um programa social problemático que segrega a população, pela implementação de moradias longe dos serviços básicos e que não reduz eficientemente o déficit habitacional que deveria ser combatido (Jornal do Senado, 2018).

Assim posto, revela-se que ainda que o programa MCMV imprima outra direção à política habitacional no país, apesar de injetar recursos significativos na produção habitacional, constitui-se uma oportunidade de negócios para empreiteiras e incorporadoras. Pois, indicadores que serviriam como informação, avaliação e monitoramento das produções habitacionais são abandonados, criando cada vez mais cidades desproporcionais e insustentáveis entre oferta e demanda habitacional.

Logo, há de se questionar, se o Sistema de Informações das Habitações e Relatórios de Avaliações da Política, do Plano e do Programa estão operando com indicadores que identifiquem as reais condições habitacionais dos municípios para uma produção habitacional sustentável. Visto que, atualmente existem diversas críticas ao programa por não produzir habitações para as classes menos favorecidas e quando produzem, às marginalizam nas periferias com carência em infraestrutura básica. Dessa forma, quando observamos e correlacionamos as reais condições habitacionais produzidas e dados sobre o déficit habitacional urbano e $\mathrm{n}^{\circ}$ de domicílios vagos urbanos fornecido pela Fundação João Pinheiro, verificamos que as políticas habitacionais por seus objetivos, seus desafios, e seu sistema de avaliação e monitoramento possuem falhas como política. Já que o abandono de indicadores e a superprodução de habitações pelo mercado imobiliário, parecem ser a resposta para uma produção cada vez mais deficitária. 


\section{A questão habitacional no Estado do Rio Grande do Sul}

Por conseguinte, a fim de verificar e analisar as incoerências entre a produção habitacional promovida pela Política Habitacional Brasileira e indicadores habitacionais já discutidos em nível Federal no tópico anterior, nesse segundo tópico analisa-se como esse processo se apresenta em um conjunto de municípios do Estado do Rio Grande do Sul. Optouse em realizar a análise em municípios do Estado que apresentam população entre 75.000 e 300.000 habitantes e que se constituem em cidades médias que apresentam ativo processo de urbanização e desempenham importante centralidade urbana nas regiões onde se inerem. Nesse grupo de cidades selecionadas, também estão presentes cidades médias que integram a Região Metropolitana de Porto Alegre que apresentam intenso processo de urbanização. Nessas cidades medias escolhidas para a presente análise, tivemos a realização de empreendimentos do Programa MCMV, com diferentes níveis de investimentos e de volume de recursos.

A abordagem nesse tópico subdivide-se em diferentes análises comparativas. Entretanto, antes das análises, vale caracterizar três dos indicadores analisados: déficit habitacional, domicílios vagos e unidades do Programa MCMV - Faixa 1 (i.e; produção de 2009 a 2018).

Entende-se como déficit habitacional, de acordo com a Fundação João Pinheiro (2005), a inadequação de moradias que reflete em problemas na qualidade de vida dos moradores que não se relacionam apenas ao dimensionamento do estoque de habitações, mas também às especificidades desse estoque. Portanto, o déficit habitacional analisado nesse artigo engloba tanto aquelas moradias sem condições de serem habitadas devido à precariedade das construções, quanto à necessidade de incremento do estoque, decorrente da coabitação familiar ou da moradia em locais destinados a fins não residenciais.

Os domicílios vagos são caracterizados, conforme o IBGE, como aqueles que não tinham morador na data de referência, mesmo que, posteriormente, durante o período da coleta, tivessem sido ocupados. Portanto casas colocadas à venda (ou de aluguel) e abandonadas foram caracterizadas como domicílios vagos. De acordo com a CAIXA - MCMV, famílias com renda de até $\mathrm{R} \$ 1.800,00$ são beneficiadas com empreendimento Faixa 1. O financiamento de até 120 meses, com prestações mensais que variam de $\mathrm{R} \$ 80,00$ a $\mathrm{R} \$ 270,00$, conforme a renda bruta familiar.

Portanto, esse artigo buscou analisar, a partir desses indicadores, se a Política Nacional de Habitação considerou de forma ampla dois dos principais problemas encontrados pelo diagnóstico sobre a questão habitacional: o déficit habitacional e o problema dos domicílios vagos.

Barbarói, Santa Cruz do Sul, n. 56, p.<261-281>,jan./jun. 2020 


\section{- População, déficit habitacional urbano e domicílios vagos urbanos}

Conforme Figura 1, observa-se que os municípios do Estado do Rio Grande do Sul com maior população são os que possuem maior déficit habitacional urbano e $\mathrm{n}^{\circ}$ de domicílios vagos urbano em 2010. Visto que é inegável que as maiores cidades brasileiras e gaúchas possuem mais carências habitacionais.

Figura 1 - Déficit Habitacional Urbano e Domicílios Vagos Urbanos em 2010 no Estado do RS.

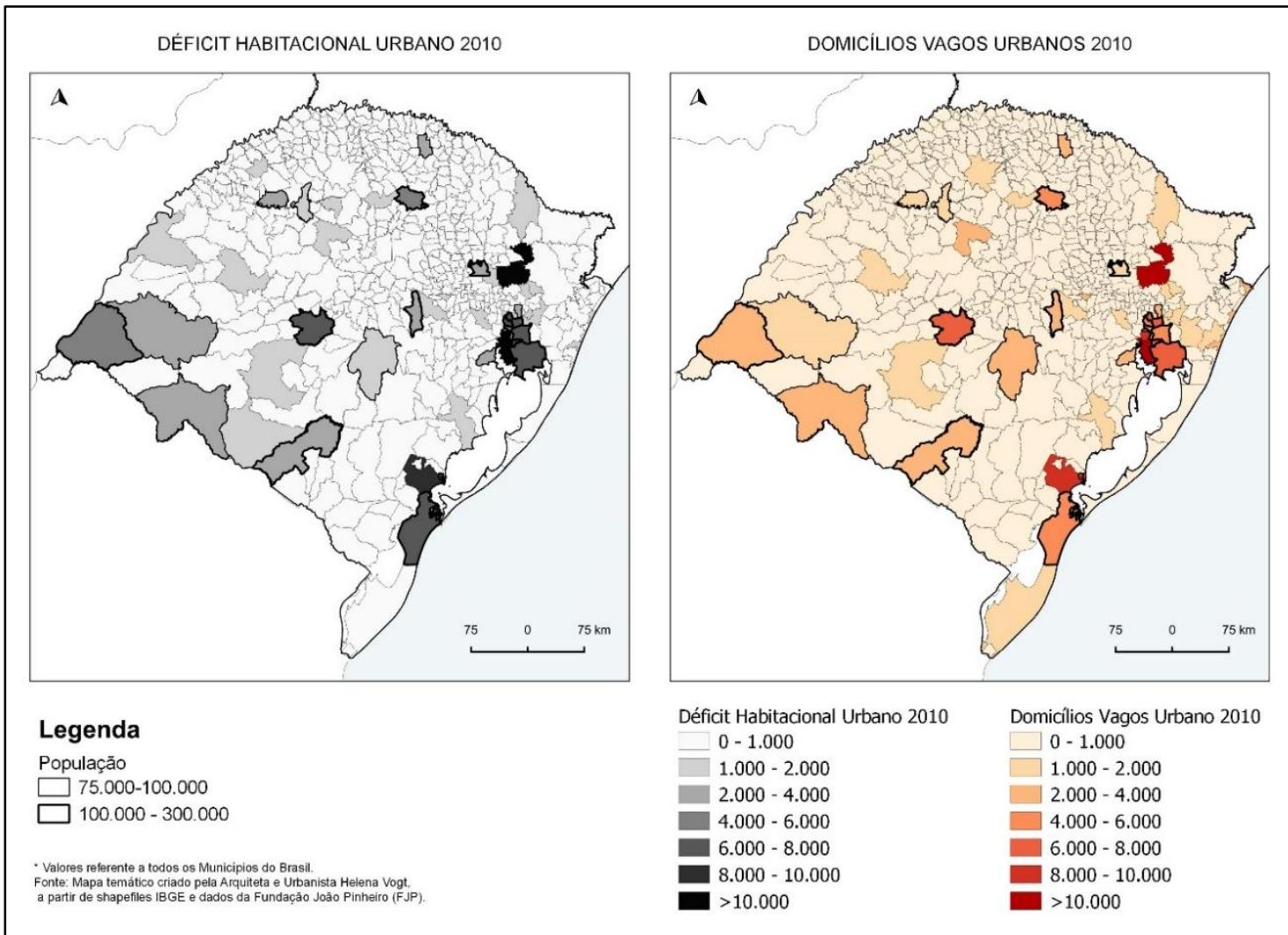

Fonte: Mapa temático produzido pela autora a partir de dados fornecidos pela Fundação João Pinheiro e IBGE 2010.

Entretanto, dos municípios analisados na Figura 1, que possuem entre 75.000 a 300.00 hab. e a Capital do Estado do Rio Grande do Sul - todos possuem mais do que $40 \%$ do $\mathrm{n}^{\mathrm{o}}$ de domicílios vagos urbanos do que seu déficit habitacional urbano (Tabela 3), tendo como média 83,2\%. Assim, tornar-se-ia desnecessária uma superprodução habitacional, se houvesse o aproveitamento das habitações vazias já existentes, através da criação de aluguéis sociais pagos pelo Estado, valorizando assim os recursos públicos e evitando o desperdício dos recursos públicos. Pois, além de garantir e dar uso social para o ambiente já construído nas cidades, aproveitando as áreas já urbanizadas e com infraestrutura já instaladas, não haveria necessidade de ampliação da área urbana. 
Tabela 3 - Déficit Habitacional Urbano x Domicílios Vagos Urbano em 2010 em Municípios de 75.000 a 300.000 hab. e capital.

\begin{tabular}{lrrr}
\hline & $\begin{array}{r}\text { déficit habitacional } \\
\text { urbano 2010 (a) }\end{array}$ & $\begin{array}{r}\text { domicílios vagos } \\
\text { urbano 2010 (b) }\end{array}$ & $\begin{array}{r}\text { (b) / (a) } \\
* \mathbf{1 0 0}\end{array}$ \\
\hline Santa Maria & 8.053 & 6.865 & $85,2 \%$ \\
\hline Gravataí & 7.739 & 5.971 & $77,2 \%$ \\
\hline São Leopoldo & 7.196 & 5.784 & $80,4 \%$ \\
\hline Novo Hamburgo & 7.012 & 6.314 & $90,0 \%$ \\
\hline Viamão & 6.665 & 7.275 & $109,2 \%$ \\
\hline Alvorada & 6.640 & 4.802 & $72,3 \%$ \\
\hline Rio Grande & 6.277 & 5.935 & $94,6 \%$ \\
\hline Passo Fundo & 5.691 & 4.281 & $75,2 \%$ \\
\hline Uruguaiana & 4.860 & 2.098 & $43,2 \%$ \\
\hline Sapucaia Do Sul & 4.158 & 3.185 & $76,6 \%$ \\
\hline Cachoeirinha & 3.658 & 2.757 & $75,4 \%$ \\
\hline Bagé & 3.449 & 2.771 & $80,3 \%$ \\
\hline Guaíba & 3.014 & 2.415 & $80,1 \%$ \\
\hline Santa Cruz Do Sul & 2.967 & 2.586 & $87,2 \%$ \\
\hline Erechim & 2.753 & 2.129 & $77,3 \%$ \\
\hline Bento & 2.661 & 1.715 & $64,4 \%$ \\
\hline Santana Do Livramento & 2.608 & 2.202 & $84,4 \%$ \\
\hline Sapiranga & 2.234 & 2.367 & $106,0 \%$ \\
\hline Santo Ângelo & 2.159 & 1.769 & $81,9 \%$ \\
\hline Alegrete & 2.094 & 1.139 & $54,4 \%$ \\
\hline Esteio & 2.085 & 2.038 & $97,7 \%$ \\
\hline Cachoeira Do Sul & 1.869 & 2.340 & $125,2 \%$ \\
\hline Ijuí & 1.808 & 1.465 & $81,0 \%$ \\
\hline Fon & & & \\
\hline
\end{tabular}

Fonte: Formulação da tabela pela autora a partir de dados fornecidos pela Fundação João Pinheiro, 2010.

Sendo que, conforme Tabela 3, os municípios que possuem maiores percentuais de domicílios vagos urbanos sobre seu déficit habitacional são os próximos a região metropolitana de Porto Alegre, e os que possuem menor percentual são os da periferia leste do Rio Grande do sul, como Alegrete e Uruguaiana. Mas, a partir desses dados quando localizados em mapa, observe-se conforme Figura 2, que os maiores percentuais de domicílios vagos urbanos sobre o déficit habitacional urbano são: os municípios do litoral oeste onde existe superprodução para atender a locação de moradias no verão e o turismo; os municípios periféricos às cidades médias nos quais parte da população migrou para aquelas centralidades regionais; os municípios da extremidade sudeste que sofreu em anos anteriores queda econômica após grandes Barbarói, Santa Cruz do Sul, n. 56, p.<261-281>,jan./jun. 2020 
investimentos ligado ao polo naval e petroquímico; e alguns pequenos municípios ao norte do Estado em razão das crises econômicas promovidas pelas estiagens e/ou pelo avanço do agronegócio e sua consequente concentração de terras e redução na mão de obra ocupada.

Figura 2- \% Domicílios Vagos Urbanos / Déficit Habitacional Urbano 2010 no RS.

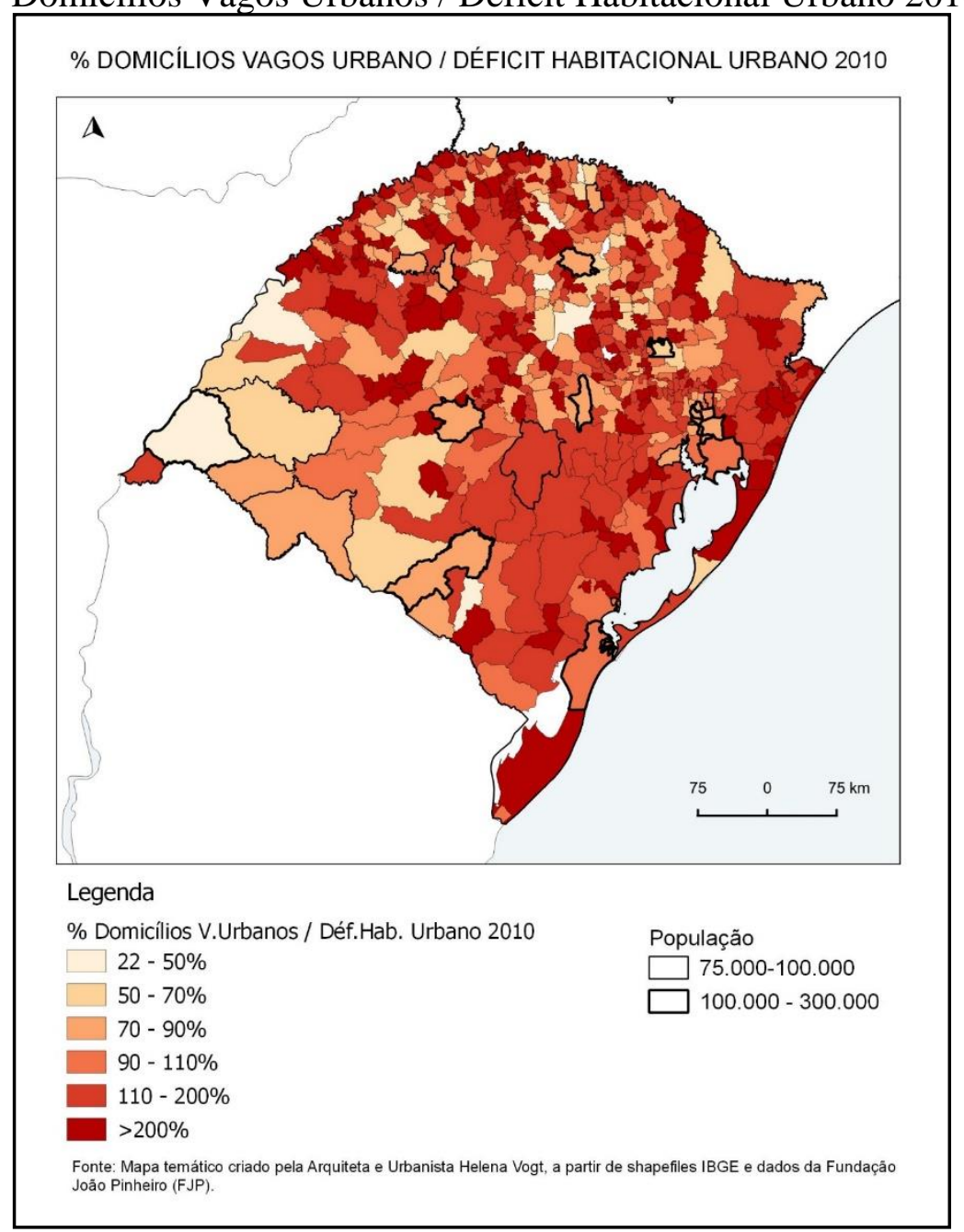

Fonte: Mapa temático produzido pela autora a partir de dados fornecidos pela Fundação João Pinheiro e IBGE 2010 .

O que nos leva a problematizar que o déficit habitacional em questão não demonstra ser significativo no território estadual. Visto que existem praticamente em todos os municípios do Estado, domicílios vagos urbanos que poderiam sanar o déficit habitacional estadual se ocupados. Mesmo que de acordo com a Lei no 10.257, de 10 de julho de 2001, a função social da propriedade, pelo Estatuto da Cidade forneça diretrizes aos municípios quanto a esses indicadores habitacionais, já que:

Art. $2^{\circ}$ - A política urbana tem por objetivo ordenar o pleno desenvolvimento das funções sociais da cidade e da propriedade urbana: VI - ordenação e controle do uso do solo, de forma a evitar: a) a utilização inadequada dos imóveis urbanos; e) a retenção especulativa de imóvel urbano, que resulte na sua subutilização ou não utilização;

Barbarói, Santa Cruz do Sul, n. 56, p.<261-281>,jan./jun. 2020 
Portanto, a existência de números tão expressivos nos municípios do Estado do Rio Grande do Sul, como verificado, demonstra o quanto é difícil a efetividade dessa função social.

\section{- O déficit habitacional urbano e a produção MCMV (faixa 1)}

A existência de expressivo número de domicílios vagos urbanos nas cidades selecionadas parece não ser suficiente para sanar o déficit habitacional urbano desses municípios e tão pouco para atender as diretrizes do Estatuto da Cidade (LANNOY, 2006). Isso fica evidente quando se analisa em conjunto os dados da produção de unidades habitacionais para classe baixa (i.e., Faixa 1) fornecido pela Caixa Federal (i.e.; de 2009 a 2018). Buscamos verificar então se essa produção está correlacionada com os indicadores municipais de déficit habitacional urbano para sanar tal problema habitacional, e, assim, ir-se ao encontro dos objetivos das políticas habitacionais discutidas no tópico anterior.

Quando se observa a porcentagem da produção de unidades do MCMV- Faixa 1 em relação ao déficit habitacional urbano de cada um dos municípios, verifica-se que essa não é proporcional ao déficit habitacional (Tabela 4). A título de exemplo, entre 2009 e 2018, os municípios de Bagé e Santa Cruz do Sul receberam praticamente 50\% de unidades MCMV Faixa 1 em relação ao seu déficit habitacional. No mesmo período, municípios como Cachoeirinha e Guaíba não receberam nem 1\% de unidades do MCMV - Faixa 1 em relação ao seu déficit. O que nos faz refletir sobre a existência de outros fatores externos que podem ter influenciado a produção de unidades MCMV- Faixa 1, além dos indicadores habitacionais. Entre eles, há que se considerar o interesse e a mobilização do governo municipal e da iniciativa privada dos municípios na busca de recursos federais do Programa MCMV, independente dos indicadores relativos à oferta de moradias vazias, visando atender a demanda e as reivindicações da população que vive em situação irregular nessas cidades. Não há também interesse e vontade política do governo municipal em promover a desapropriação de imóveis, ou mesmo a institucionalização do aluguel social para fins de implementação do direito à moradia para a população de baixa renda que reside na cidade. As relações de poder e os interesses cruzados entre os representantes e agentes do mercado imobiliário e os agentes políticos do executivo ou legislativo municipal, no processo de expansão, ocupação e uso do solo urbano, são uma constante na urbanização dessas cidades e acabam produzindo uma legislação urbanística e de planejamento territorial que favorece mais os ganhos privados dos proprietários fundiários e promotores imobiliários, do que aos interesses coletivos da população, sobretudo daquela parcela mais pobre que ainda não acessou sua moradia própria e não tem direito à cidade. 
Tabela 4 - Déficit Habitacional Urbano x Produção de Unidades MCMV- Faixa 1

\begin{tabular}{|c|c|c|c|}
\hline & $\begin{array}{r}\text { déficit habitacional } \\
\text { urbano } 2010 \text { (a) }\end{array}$ & $\begin{array}{r}\text { produção unidades } \\
\text { MCMV faixa } 1(2009- \\
2018)(b)\end{array}$ & $\begin{array}{r}\text { (b) } / \text { (a) } \\
* 100\end{array}$ \\
\hline Santa Maria & 8.053 & 1.940 & $24,1 \%$ \\
\hline Gravataí & 7.739 & 2.174 & $28,1 \%$ \\
\hline São Leopoldo & 7.196 & 2.784 & $38,7 \%$ \\
\hline Novo Hamburgo & 7.012 & 1.380 & $19,7 \%$ \\
\hline Viamão & 6.665 & 1.249 & $18,7 \%$ \\
\hline Alvorada & 6.640 & 1.604 & $24,2 \%$ \\
\hline Rio Grande & 6.277 & 1.962 & $31,3 \%$ \\
\hline Passo Fundo & 5.691 & 809 & $14,2 \%$ \\
\hline Uruguaiana & 4.860 & 1.547 & $31,8 \%$ \\
\hline Sapucaia Do Sul & 4.158 & 1.053 & $25,3 \%$ \\
\hline Cachoeirinha & 3.658 & 0 & $0,0 \%$ \\
\hline Bagé & 3.449 & 1.722 & $49,9 \%$ \\
\hline Guaíba & 3.014 & 7 & $0,2 \%$ \\
\hline Santa Cruz Do Sul & 2.967 & 1.477 & $49,8 \%$ \\
\hline Erechim & 2.753 & 257 & $9,3 \%$ \\
\hline Bento & 2.661 & 420 & $15,8 \%$ \\
\hline Santana Do Livramento & 2.608 & 626 & $24,0 \%$ \\
\hline Sapiranga & 2.234 & 813 & $36,4 \%$ \\
\hline Santo Ângelo & 2.159 & 876 & $40,6 \%$ \\
\hline Alegrete & 2.094 & 643 & $30,7 \%$ \\
\hline Esteio & 2.085 & 952 & $45,7 \%$ \\
\hline Cachoeira Do Sul & 1.869 & 304 & $16,3 \%$ \\
\hline Ijuí & 1.808 & 1.151 & $63,7 \%$ \\
\hline
\end{tabular}

Fonte: Formulação da tabela pela autora a partir de dados fornecidos pela Fundação João Pinheiro e CAIXA MCMV.

O desempenho e o comportamento dos indicadores nos municípios selecionados, conforme o mapa temático na Figura 3, demonstram que além dos municípios selecionados na Tabela 4, a produção de unidades do MCMV - Faixa 1 também não é proporcional ao déficit habitacional urbano, nos demais municípios, ainda que haja diferenças na intensidade desses desempenhos.

As cidades médias de 100.000 a 300.000 hab., possuem menor percentual de produção do MCMV - Faixa 1/Déficit Habitacional Urbano do que seus municípios periféricos, mesmo essas possuindo maiores valores de déficit habitacional e unidades de produção MCMV - Faixa 
1. E os municípios ao norte do Estado, que por sua vez possuem os menores valores de déficit habitacional, de forma contraditória receberam mais de 300\% de unidades do MCMV - Faixa 1 durante o período de 2009 a 2018 em comparação ao seu déficit habitacional urbano no ano de 2010.

Figura 3 - Déficit Hab. X Produção MCMV - Faixa 1 X \%Déficit Hab. / Produção MCMV Faixa 1

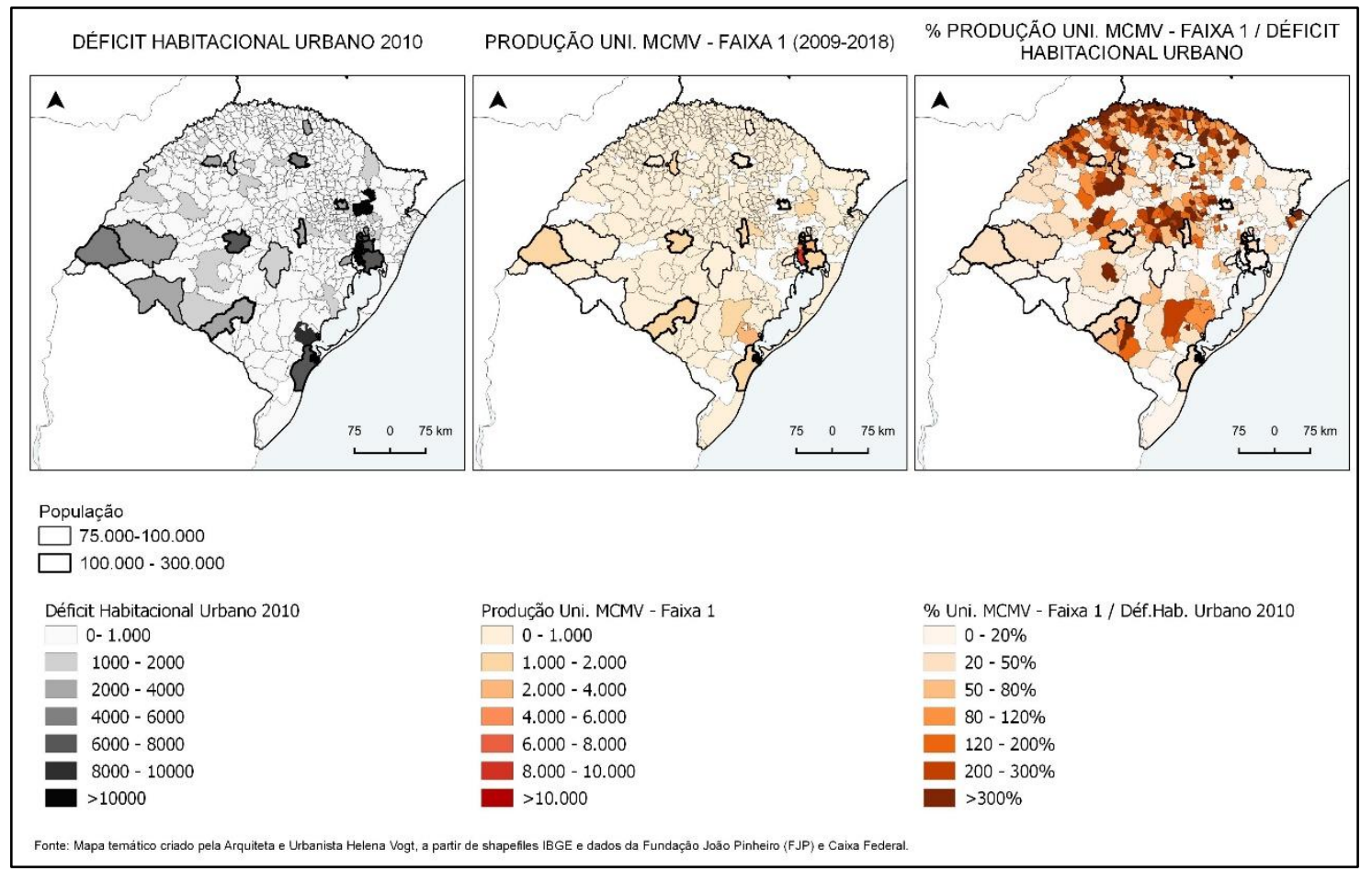

Fonte: Mapa temático produzido pela autora a partir de dados fornecidos pela Fundação João Pinheiro e IBGE 2010 e Caixa Federal.

O que novamente, releva o questionamento sobre o descompasso entre as políticas e os indicadores habitacionais no Brasil para uma efetiva, justa e proporcional diminuição de problemas habitacionais como o os domicílios vagos urbanos e o déficit habitacional urbano nos municípios com situação mais alarmante.

\section{- Déficit habitacional urbano, domicílios vagos urbano e produção MCMV}

Já a fim de analisar o descompasso entre as políticas e os indicadores habitacionais no Brasil, observamos, conforme Tabela 5, que a porcentagem de 1/3 dos municípios ultrapassa $40 \%$ de unidades do MCMV para o $\mathrm{n}^{\circ}$ de domicílios vagos urbanos. Verificamos ainda que essa \% não está relacionada com os municípios com maior déficit habitacional urbano. Se considerarmos a diferença entre o déficit habitacional urbano e o $\mathrm{n}^{\circ}$ de domicílios vagos urbanos 
somados a produção de unidades MCMV - Faixa 1, veremos que há, na maior parte dos municípios, menores déficits habitacionais e até há a existência de estoque de moradias, como é o caso de Cachoeira do Sul, se levado em conta os domicílios vagos.

Tabela 5 - Domicílios Vagos Urbano x Produção Unidades MCMV - Faixa 1

$\begin{array}{rrrrr}\text { déficit } & \text { domicílios } & \text { produção unidades } & \text { (c) / ‘(b) } & \text { (a) - (b) } \\ \text { habitacional } & \text { vagos urbano } & \text { MCMV faixa } 1 & * 100 & +(\text { c) } \\ \text { urbano 2010 } & 2010(\text { b) } & (2010-2018)(c) & & \end{array}$

(a)

2010 (b) (2010-2018) (c)

\begin{tabular}{|c|c|c|c|c|c|}
\hline Santa Maria & 8.053 & 6.865 & 1.940 & $28 \%$ & 3.128 \\
\hline Gravataí & 7.739 & 5.971 & 2.174 & $36 \%$ & 3.942 \\
\hline São Leopoldo & 7.196 & 5.784 & 2.784 & $48 \%$ & 4.196 \\
\hline Novo Hamburgo & 7.012 & 6.314 & 1.380 & $22 \%$ & 2.078 \\
\hline Viamão & 6.665 & 7.275 & 1.249 & $17 \%$ & 639 \\
\hline Alvorada & 6.640 & 4.802 & 1.604 & $33 \%$ & 3.442 \\
\hline Rio Grande & 6.277 & 5.935 & 1.962 & $33 \%$ & 2.304 \\
\hline Passo Fundo & 5.691 & 4.281 & 809 & $19 \%$ & 2.219 \\
\hline Uruguaiana & 4.860 & 2.098 & 1.547 & $74 \%$ & 4.309 \\
\hline Sapucaia Do Sul & 4.158 & 3.185 & 1.053 & $33 \%$ & 2.026 \\
\hline Cachoeirinha & 3.658 & 2.757 & 0 & $0 \%$ & 901 \\
\hline Bagé & 3.449 & 2.771 & 1.722 & $62 \%$ & 2.400 \\
\hline Guaíba & 3.014 & 2.415 & 7 & $0 \%$ & 606 \\
\hline Santa Cruz Do Sul & 2.967 & 2.586 & 1.477 & $57 \%$ & 1.858 \\
\hline Erechim & 2.753 & 2.129 & 257 & $12 \%$ & 881 \\
\hline Bento Gonçalves & 2.661 & 1.715 & 420 & $24 \%$ & 1.366 \\
\hline $\begin{array}{l}\text { Santana do } \\
\text { Livramento }\end{array}$ & 2.608 & 2.202 & 626 & $28 \%$ & 1.032 \\
\hline Sapiranga & 2.234 & 2.367 & 813 & $34 \%$ & 680 \\
\hline Santo Ângelo & 2.159 & 1.769 & 876 & $50 \%$ & 1.266 \\
\hline Alegrete & 2.094 & 1.139 & 643 & $56 \%$ & 1.598 \\
\hline Esteio & 2.085 & 2.038 & 952 & $47 \%$ & 999 \\
\hline Cachoeira do Sul & 1.869 & 2.340 & 304 & $13 \%$ & -167 \\
\hline Ijuí & 1.808 & 1.465 & 1.151 & $79 \%$ & 1.494 \\
\hline
\end{tabular}

Fonte: Formulação da tabela pela autora a partir de dados fornecidos pela Fundação João Pinheiro e CAIXA MCMV.

Portanto, a produção de unidades do MCMV - Faixa 1, embora incorporada ao Plano Nacional de Habitação apresenta nítido descompasso com os indicadores habitacionais.

$\mathrm{Na}$ Figura 4, o mapa temático relaciona diferentes realidades: o déficit habitacional Barbarói, Santa Cruz do Sul, n. 56, p.<261-281>,jan./jun. 2020 
urbano municipal de 2010; e a diferença do déficit habitacional pelo $\mathrm{n}^{\circ}$ de domicílios vagos somado a produção de unidades MCMV - Faixa 1. O que demonstra que no segundo caso, alguns municípios possuiriam em 2020 até incremento de estoque para poder sanar os novos cálculos de déficit habitacional.

Figura 4 - Déficit hab. urbano 2010 x Diferença de indicadores

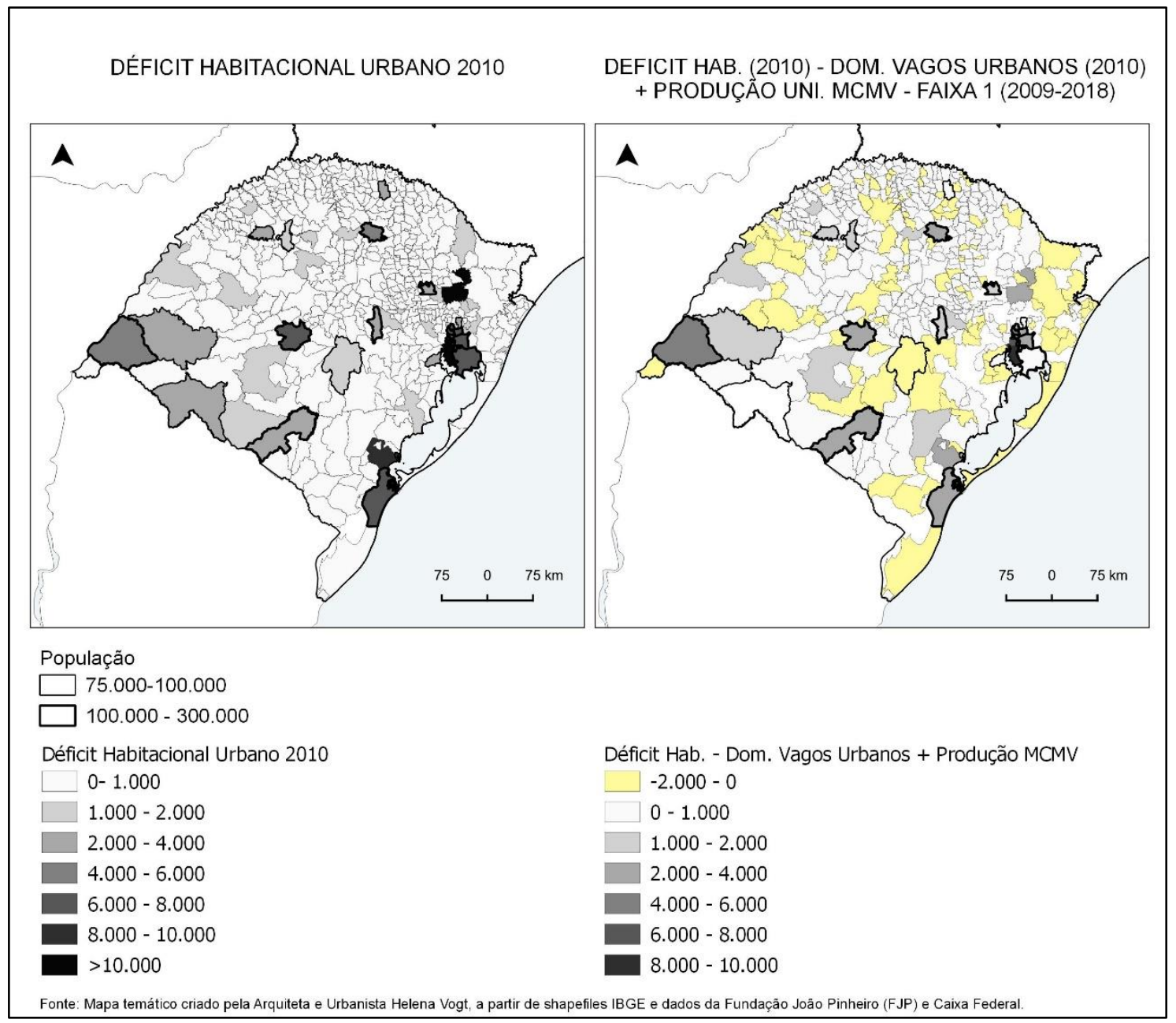

Fonte: Mapa temático produzido pela autora a partir de dados fornecidos pela Fundação João Pinheiro e IBGE 2010 e Caixa Federal.

Logo se os domicílios vagos urbanos fossem utilizados para sanar o déficit habitacional, e se a produção do MCMV - Faixa 1 fosse produzida em maior escala, proporcionalmente em municípios onde a necessidade de habitação é maior, em 2020 os novos indicadores habitacionais dos municípios seriam menos desiguais regionalmente, e o planejamento urbano estaria na direção da função social do solo. 


\title{
Considerações finais
}

Os dados analisados permitem inferir que a demanda pela produção de novas habitações para atender o déficit habitacional existente nos municípios, talvez deva ser relativizada ou calculada proporcional a seu déficit, já que os municípios possuem domicílios urbanos vagos (i.e. domicílios fechados; domicílios de uso ocasional; domicílios desocupados ${ }^{3}$ ) cujo montante é proporcional ao seu déficit habitacional urbano.

Em suma, assim como as políticas habitacionais enfrentam dificuldades ao sanar o déficit habitacional no Brasil, os municípios do Estado do Rio Grande do Sul também não obtiveram sucesso. Em ambos os níveis administrativos, Federal e Municipal, não fora atingido satisfatoriamente todos os seus objetivos como foram planejados em relação ao déficit habitacional e ao problema dos domicílios vagos. Entendemos que o território dos municípios, notadamente suas áreas urbanas, deveriam ser planejados e regulados por políticas públicas coesas, no entanto o que se observa é que nos mesmos acabam prevalecendo uma configuração e ampliação espacial, dos espaço construído e urbanizado, de modo desproporcional e sem observar concretamente aos seus indicadores habitacionais efetivamente existentes.

Por fim, entende-se que a análise desse processo requer avançar a pesquisa através de novas investigações sobre a localização de todos empreendimentos do Programa MCMV, bem como de outras habitações sociais, e dos domicílios vagos urbanos nos municípios selecionados. Tais ações, seriam de fundamental importância para se confirmar as evidências acima registradas, ou mesmo para melhor compreender as razões que envolvem tanto o setor imobiliário, quanto os agentes governamentais e locais e os incentivos fiscais, regulações e leis complementares municipais, em sua relação ou contradição com a Política Habitacional Brasileira.

\section{THE DISPATCH BETWEEN POLICIES AND HOUSING INDICATORS IN BRAZIL: AN ANALYSIS IN MUNICIPALITIES IN STATE OF RIO GRANDE DO SUL}

\begin{abstract}
The intense and unequal urbanization of Brazilian cities has been characterized by presenting, among other problems, a recurring housing deficit, arising from a speculative real estate market and the lack or insufficiency of including public policies. But what is the real situation of the Brazilian housing? Do the objectives and implementation of the recent national housing policy effectively take into account the existing indicators on the housing deficit and the number of

\footnotetext{
${ }^{3}$ Domicílios fechados - são conceituados como domicílios particulares permanentes cujos moradores estavam ausentes por ocasião do período de coleta do censo; domicílios de uso ocasional - são aqueles que servem ocasionalmente de moradia: casas de campo, de fim-de-semana, férias etc.; domicílios vagos - são as unidades que se encontravam efetivamente desocupadas na data de referência do censo demográfico. (FJP, 2005).
}

Barbarói, Santa Cruz do Sul, n. 56, p.<261-281>,jan./jun. 2020 
vacant urban properties in Brazilian municipalities? This article briefly discusses these issues and the inconsistencies between the objectives of recent housing policies and the real situation of the urban housing deficit in Brazil, analyzing more specifically this process in selected municipalities in Rio Grande do Sul. Methodologically, the analysis was done through from the correlation of secondary data from the Fundação João Pinheiro (FJP), the Instituto Brasileiro de Geografia e Estatística (IBGE) and the Caixa Federal referring to the indicators of the municipal population, urban housing deficit, number of urban vacant homes and housing production of the Housing Program Minha Casa Minha Vida - MCMV (Track 1), in municipalities of 75,000 to 300,000 inhabitants in the State of Rio Grande do Sul. It is concluded that there is dispatch between the objectives of policies and indicators of the real housing situation, highlighting the need for assessments and monitoring of public policies in the territory that notice and value the housing indicators of the municipalities.

Keywords: Housing Policy; Housing indicators; Minha Casa Minha Vida.

\section{EL DESAJUSTE ENTRE POLÍTICAS E INDICADORES DE VIVIENDA EN BRASIL: UN ANÁLISIS DE MUNICIPIOS EN EL ESTADO DE RÍO GRANDE DO SUL}

\section{Resumen}

La urbanización intensa y desigual de las ciudades brasileñas se ha caracterizado por presentar, entre otros problemas, un déficit habitacional recurrente, derivado de un mercado inmobiliario especulativo y la falta o insuficiencia de políticas públicas inclusivas. ¿ Pero, cuál es la realidad de la situación de la vivienda brasileña? ¿Los objetivos y la implementación de la reciente política nacional de vivienda tienen efectivamente en cuenta los indicadores existentes sobre el déficit de vivienda y el número de propiedades urbanas vacantes en los municipios brasileños? Este artículo discute brevemente estos problemas y las inconsistencias entre los objetivos de las políticas de vivienda recientes y la situación real del déficit de vivienda urbana en Brasil, analizando más específicamente este proceso en municipios seleccionados en Rio Grande do Sul. Metodológicamente, el análisis se lleva a cabo desde la correlación de datos secundarios de la Fundação João Pinheiro (FJP), el Instituto Brasileiro de Geografia e Estatística (IBGE) y la Caixa Federal en referencia a los indicadores de población municipal, déficit de viviendas urbanas, número de viviendas urbanas vacantes y producción de viviendas del Programa de Vivienda Minha Casa Minha Vida-MCMV (Carril 1), en municipios de 75,000 a 300,000 habitantes en el estado de Rio Grande do Sul. Se concluye que existen desajustes entre los objetivos de las políticas y los indicadores de la situación real de la vivienda, destacando la necesidad de evaluaciones y monitoreo de políticas públicas en el territorio que monitorear y mejorar los indicadores de vivienda de los municipios.

Palabras clave: Política de vivienda; Indicadores de vivienda; Minha Casa Minha Vida.

\section{REFERÊNCIAS}

AZEVEDO, Sérgio de; ANDRADE, Luís Aureliano Gama de. Habitação e Poder: da Fundação da Casa Popular ao Banco Nacional da Habitação. Rio de Janeiro: Zahar, 135p., 1982.

BOLAFFI, Gabriel. Habitação e urbanismo: o problema e o falso problema. Centro de Estudos Rurais e Urbanos: Cadernos n09: 1976. 
BONDUKI, N. Política habitacional e inclusão social no Brasil: revisão histórica e novas perspectivas no governo Lula. Revista Eletrônica de Arquitetura e Urbanismo, São Paulo: n. 1, p. $70-104,2008$.

CAIXA. Download - Empreendimentos Minha Casa Minha Vida. Disponível em: http://www.caixa.gov.br/poder-publico/programas-uniao/habitacao/minha-casa-minhavida/Paginas/default.aspx/saiba_mais.asp >. Acesso em: 15 jan. 2020.

DOMINGOS, Nadion Florindo; FERNANDES JUNIOR, Valtair. O déficit habitacional no Brasil frente às políticas públicas de habitação. Anais do Seminário Científico da FACIG, n. 2, p.01-07, 2017.ESTATUTO DA CIDADE. Brasília: Senado Federal, Subsecretaria de Edições Técnicas, 3. ed., 2017.

FUNDAÇÃO JOÃO PINHEIRO. Centro de Estatística e Informações. Déficit Habitacional Municipal no Brasil 2015: Belo Horizonte, 2018.

FUNDAÇÃO JOÃO PINHEIRO. Centro de Estatística e Informações. Déficit Habitacional Municipal no Brasil 2010: Belo Horizonte, 2013.

FUNDAÇÃO JOÃO PINHEIRO, Centro de Estatística e Informações. Déficit habitacional no Brasil, municípios selecionados e microrregiões geográficas: 2. ed. - Belo Horizonte, 2005.

FUNDAÇÃO JOÃO PINHEIRO. Déficit habitacional referência 2010: Banco de dados pelo instalador da Fundação João Pinheiro. Disponível em: http://novosite.fjp.mg.gov.br/deficithabitacional-no-brasil/ >. Acesso em: 27 jan. 2020.

IBGE. Base de Informações do Censo Demográfico 2010: Resultado do Universo por setor censitário: Rio de Janeiro, 2011.

IBGE. Censo demográfico 2010: Banco de dados agregados do IBGE. Disponível em: https://www.ibge.gov.br/estatisticas/downloads-estatisticas.html >. Acesso em: 27 jan. 2020 .

JORNAL DO SENADO. Minha Casa Minha Vida não reduziu déficit habitacional, afirma estudo. Brasília: 20 de fevereiro de 2018.

LANNOY, Camilo Pablo de. O descompasso das políticas públicas para a solução do déficit habitacional. 2006. 151 f. Dissertação (Mestrado em Arquitetura e Urbanismo) -Universidade de Brasília, Brasília, 2006.

MINISTÉRIO DAS CIDADES. Plano Nacional de Habitação: 2009.

MINISTÉRIO DAS CIDADES. Déficit Habitacional Municipal no Brasil 2010: Belo Horizonte, novembro de 2013.

MINISTÉRIO DAS CIDADES. Política Nacional De Habitação: Caderno 4 Mcidades Habitação, 2004.

SANTOS, Milton. A natureza do espaço - técnica e tempo, razão e emoção. São Paulo: Hucitec, 1996. 
SILVA, M. L. da.; TOURINHO, H. L. Z. O Banco Nacional de Habitação e o Programa Minha Casa Minha Vida: duas políticas habitacionais e uma mesma lógica locacional. Cad. Metrópoles.: São Paulo, v. 17, n. 34, pp. 401-417, 2015.

Data de recebimento: $27 / 01 / 2020$

Data de aceite: 08/04/2020

\section{Sobre os autores:}

Helena de Moura Vogt é Mestre em Desenvolvimento Regional (UNISC), e graduada em Arquitetura e Urbanismo pela Pontifícia Universidade Católica do Rio Grande do Sul (PUCRS). Atualmente participa do projeto ObservaDR COVID-19 na elaboração de mapas temáticos com intenção de fornecer informações úteis ao planejamento de ações e à tomada de decisões para a prevenção e combate à pandemia ocasionada pela expansão do coronavírus, bem como oferecer informações científicas para o conjunto da sociedade. Também trabalha com análises técnicas ambientais para revisões de planos diretores municipais, pela elaboração de mapas temáticos e análises urbanísticas. Endereço Eletrônico: helenamvogt@gmail.com

Rogério Leandro Lima da Silveira é Mestre e Doutor em Geografia Humana pela Universidade Federal de Santa Catarina. Pesquisador do CNPq - 2. Professor titular e pesquisador do Departamento de História e Geografia, e pesquisador e orientador no Programa de PósGraduação em Desenvolvimento Regional - Mestrado e Doutorado, da Universidade de Santa Cruz do Sul. É lider do GEPEUR - Grupo de Pesquisa e Estudos Urbanos Regionais (CNPq). Pesquisador Visitante do Centro Interdisciplinar de Ciências Sociais da Universidade Nova de Lisboa - CICS.NOVA Coordenador do Observatório do Desenvolvimento Regional. Endereço Eletrônico: rlls@unisc.br 